\title{
Folkhemmets demokrati
}

- en analys av den svenska socialdemokratins språkbruk kring demokratiska deltagandeformer

Få begrepp omges av det symboliska värde som demokratibegreppet erhållit under 1900-talet. Att argumentera för en nedmontering av demokratin tycks idag vara otänkbart för varje seriös politiker. Emellertid finns en stor mängd uppfattningar om vad ett demokratiskt samhälle, eller en demokratisk stat, egentligen innebär. Vilka värderingar och principer är centrala för demokratin? Begreppet demokrati kommer från de grekiska orden demos (folk) och kratos (styre), vilket innebär att demokrati kan definieras i termer av folkstyre. Hur har denna definition tolkats inom politiken? Vilken form av folkligt styre, eller deltagande, har uppfattats som centralt för ett demokratiskt samhälle? Föreliggande artikel avser att diskutera dessa frågor genom en analys av demokratibegreppet, så som det användes av Sveriges socialdemokratiska arbetareparti (SAP) under 1920-talet, det vill säga tiden efter den allmänna och lika rösträttens införande i Sverige.

Rösträttsreformen 1919/1921 har stundtals uppfattats som kulmen på den demokratiseringsprocess som startades under slutet av 1800-talet. Emellertid har man inom socialdemokratin uppfattat demokrati som något betydligt mer än endast en form för politiskt beslutsfattande, vilket bland annat synliggjorts i socialdemokratiska uttalanden om att vidga de demokratiska principerna till fler samhällsområden än det politiska. Det socialdemokratiska demokratibegreppet har således placerats i olikartade kontexter där det uppfattats skänka legitimitet åt olika typer av samhällsreformer. I det följande analyseras ett antal sammansatta demokratibegrepp som alla användes av SAP under 1920-talet. Resultaten visar hur demokratins deltagande element gavs ett gradvis minskat utrymme, i synnerhet då begreppet demokrati kom att integreras under folkhemsbegreppet.

I en internationell jämförelse framstår den svenska processen mot allmän och lika rösträtt som tämligen likartad den i resten av 
Skandinavien. Med globala mått mätt genomfördes rösträttsreformer i dessa nationer förhållandevis tidigt. I Sverige, Danmark och Norge var kampen för en rösträttsreform en strid där arbetare organiserade sig tillsammans med bönder och liberaler. Emellertid var balansen mellan de olika grupperingarna annorlunda i Sverige än i övriga skandinaviska nationer då den svenska arbetarrörelsen gradvis växte sig allt starkare. Sålunda kom den att spela en dominerande roll för den svenska samhällsutvecklingen (Premfors 2003). "Fallet Sverige" kan därmed betraktas som en representant för den skandinaviska samhällsutvecklingen och dess demokratiseringsprocesser, men det kan samtidigt ses som ett särfall med en betydligt mer tongivande socialdemokrati än vad som var fallet i resten av Skandinavien och övriga Europa.

Demokratiforskning utgör ett av de största områdena för samhällsvetenskaplig forskning. Det finns ett stort antal redogörelser för demokratins historia: från det antika Grekland, via Rousseau och den franska revolutionen, från Montesquieu via de Tocqueville och fram till modern tid. I de nordiska länderna har forskare ofta framhållit nationernas långa tradition av demokratiska beslut, vilken i Sverige ofta härleds till 1700-talets frihetstid (se t.ex. von Sydow 1997: 13-15). Från statsvetenskapligt håll har under åren en mängd perspektiv framförts angående huruvida olika politiska system kan klassas som demokratiska eller ej (Tilly 2007; Kurki 2010). Emellertid fokuserar den övervägande majoriteten av dessa ovannämnda studier på demokrati som fenomen snarare än som begrepp. Detta innebär att forskarens egen definition ställs i centrum och tillåts styra vad som utgör en demokrati. Konsekvensen av detta förfarande är att de historiska aktörernas eget språkbruk negligeras vilket innebär en risk för anakronismer. För att undvika en historieskrivning som rör sig från nutid till dåtid - och som således påför historien dagens begrepp och värderingar - och för att erhålla en fördjupad förståelse av demokratiseringsprocesser behövs demokratistudier som tar hänsyn till den meningsskapande roll som språket de facto har (se även Kurunmäki 2012).

Föreliggande undersökning utgår från ett begreppshistoriskt perspektiv som ställer de historiska aktörerna och deras begreppsbruk i centrum. Teoretiskt baseras analysen på en kombination av två begreppshistoriska teorier: tysk Begriffsgeschichte, representerad 
av Reinhart Koselleck, och Michael Freedens teori om ideologier. Kombinationen innebär således en dualistisk tillämpning av Kosellecks kontextualism (2004: 75-92) och Freedens språkstrukturalism (2008: 47-95).

I vågorna efter första världskrigets slut upprättades en rad konstitutionella demokratier i Europa, med ett parlamentariskt system samt medborgerliga fri- och rättigheter. 1920-talet beskrevs en gång som tiden för den universella acceptansen av demokratin som styrelseform (Bryce 1929: 4). Emellertid kom hyllandet av demokratin snart att åtföljas av högljudda debatter rörande "demokratins kris" (se t.ex. Bonn 1925; Mannheim 1936; Loewenstein 1938). Situationen var densamma i Sverige, där Socialdemokraterna var starka förespråkare av den demokrati som rösträtten ansågs innebära. Från socialdemokratiskt håll uppfattades rösträttsreformen som startpunkten för förverkligandet av det samhälle som med rätta skulle kunna benämnas en fullständig demokrati (se t.ex. Olsson 1920; Karleby 1924). Liksom i övriga Europa förbyttes dock hyllandet av demokratin snart mot svenska debatter om en demokratisk kris (se t.ex. Segerstedt 1933; Tingsten 1933). I takt med att hotet om ett internationellt krig ökade kom de svenska Socialdemokraterna allt mer att avstå från kravet att bygga det fullständigt demokratiserade samhället, och istället förflyttades fokus till att bevara den form av demokrati som redan förelåg (Friberg 2013: 224-229, 249-251).

\section{Den politiska demokratins komplettering}

1919 godkände den svenska riksdagen för första gången den liberal-socialdemokratiska propositionen om allmän och lika rösträtt för män och kvinnor, men för att genomföra en grundlagsändring krävdes ytterligare en omröstning med ett mellanliggande val. Emellertid kom den andra omröstningen i hög grad att betraktas som en ren formalitet: rösträttsfrågan ansågs i praktiken vara avgjord, och den hamnade därför i bakgrunden till förmån för andra debatter (von Sydow 1997: 61; Möller 2004: 71).

Införandet av allmän och lika rösträtt har i Sverige stundtals beskrivits som "Sveriges demokratisering" (se t.ex. Hadenius 1966; Alexius 1997; Olsson 2000), men trots att reformen innebar ett tillfälligt slut på en lång och intensiv debatt var det tydligt att SAP inte 
uppfattade den som slutet på samhällets demokratisering. Snarare än en slutpunkt uppfattade Socialdemokraterna reformen som den startpunkt från vilken samhället skulle kunna bli en fullständig demokrati. 1919 skrev socialdemokraten Erik Hallin (1919: 99) i Tiden - SAP:s tidskrift för idédebatt - att: "Den politiska demokratins genombrott $\mathrm{i}$ vårt land skulle varit en meningslös händelse, ett visserligen kraftigt hugg i luften, om den icke omedelbart förde med sig en början till ekonomisk demokrati”. Rösträtten sågs som ett centralt uttryck för vad som kallades politisk demokrati, och det var utifrån nyttjandet av denna rättighet som samhället skulle kunna demokratiseras fullt ut. I en belysande studie av det danska demokratibegreppet visar Jeppe Nevers hur en förståelse av demokrati, som något mer än endast politisk rösträtt, även präglade de danska socialdemokraternas språkbruk. Parlamentarismen benämndes av Socialdemokratiet som det politiske Demokrati vilket sågs som medlet för att uppnå det absolutte Demokrati som sades vara partiets övergripande mål (Nevers 2011: 145-167).

Tidigare hade SAP intagit en tämligen tvetydig inställning till hur demokratisk parlamentarismen kunde sägas vara, och huruvida partiets företrädare skulle delta i ett eventuellt regeringssamarbete. Liknande diskussioner hade förts inom flertalet av Europas socialistiska partier som ett uttryck för den ökande sprickan mellan den ortodoxa marxismen, som bland annat gjort att det nederländska SDAP 1913 avsagt sig en regeringsplats med hänvisning till den Andra Internationalens beslut, och den reformism som framförts av framför allt Eduard Bernstein (Sassoon 2002: 47-57; Eley 2002: 83, 90). Formellt hade dock de svenska Socialdemokraterna sedan Norrköpingskongressen 1891 accepterat ett parlamentariskt styre, men i och med Lenins statskupp i november 1917 tvingades partiet entydigt att ta ställning för parlamentarismen som arbetsmetod (Isaksson 1990: 164). I synnerhet argumenterade SAP:s företrädare för att de demokratiska principer som tillämpades inom politiken skulle överföras till den industriella sfären. Det påtalades till exempel att: "politisk demokrati endast utgör det mest verksamma medlet att åstadkomma den inre nydaning i samhället, särskilt med hänsyn till den storindustriella produktionen, att detta får en alltigenom demokratisk prägel” (Palmstierna 1919: 50). 
För att manifestera att någon fullständig demokrati inte förelåg använde Socialdemokraterna sammansatta demokratibegrepp - till exempel politisk demokrati, ekonomisk demokrati och industriell demokrati - och ledande företrädare för partiet betonade ofta vikten av att komplettera den politiska demokratin. Ernst Wigforss (1920: 287), som var en av de mer inflytelserika socialdemokraterna, hävdade att politisk och ekonomisk makt inte kunde åtskiljas, vilket innebar att "en verklig politisk demokrati inte är möjlig utan en samtidig ekonomisk demokrati". Utan en ekonomisk demokrati var den svenska demokratin att betrakta som ofullständig. Fredrik Thorsson (1920), dåvarande finansminister, använde begreppet social demokrati då han hävdade att: "Det vapen [rösträtten] vi erhållit skall användas för att skaffa de tillbakasatta bättre villkor. Därför tänka vi oss också en utveckling från den politiska demokratin till den sociala". Fullständig demokrati inkluderade således flera olika former av demokrati, det var för SAP något mer än endast en form för politiskt beslutsfattande.

SAP:s demokratiuppfattning kan sägas ha speglat den syn på statens roll i samhället som sedermera kom att prägla den socialdemokratiska politiken under 1930-talets ekonomiska kris. Genom kompromisser på arbetsmarknaden, en aktiv sysselsättningspolitik och en välfärdsbyggande stat uppstod gradvis en ny bild av relationen mellan stat och samhälle, vilket i sin tur ledde till att begreppen stat och samhälle allt mer uppfattades som synonyma i den offentliga debatten (Stråth 1996: 93; Isaksson 1996: 64f). Det socialdemokratiska partiets syn på demokrati innebär för den nutida forskaren att en smal och proceduriell demokratidefinition - som nästintill förefaller vara normen inom statsvetenskaplig forskning (se t.ex. Lakoff 1996; Dahl 2000) - inte klarar av att fånga den vidd av betydelser som begreppet burit på under historien. Att enbart uppfatta demokrati som ett politiskt system med vissa institutionella arrangemang innebär ett alltför snävt perspektiv när ett historiskt ljus kastas över begreppets användning. Uppfattningar om demokrati har inte bara handlat om regler eller procedurer, utan snarare om medborgerliga livsvillkor. 


\section{Det tidiga 1920-talet: Industriel demokrati, socialisering och ekonomisk demokrati}

Frågan om industriella reformer var, efter första världskriget, ett hett debattämne i stora delar av Europa. Det industriella livet blev allt mer koncentrerat, såväl gällande ägande som lokalisering. Samtidigt minskade arbetarnas inflytande över sina arbetsvillkor då rationaliseringar inom industrin hade lett till ett högre arbetstempo, och därmed till ökade svårigheter att överblicka arbetsprocessen (Lundh 1987: 26; Schiller 1988: 33; Lundh 1989: 226). Förutom internationella influenser fanns tydliga nationella faktorer som gjorde att debatten om så kallad industriell demokrati fick fäste i Sverige. Under 1920-talet var Sverige ett av de västerländska länder som hade störst problem med strejker på arbetsmarknaden och problematiskt hög arbetslöshet (Magnusson 2000: 34f). 1920 tillsatte den socialdemokratiska regeringen en kommitté för att analysera vad som kallades Den industriella demokratiens problem. Kommitténs ordförande, Ernst Wigforss (1922a: 4), försökte att definiera begreppet industriell demokrati i följande ordalag: "Ty strävan efter demokrati inom industrin måste betyda kravet på större inflytande för arbetarna över deras arbetsvillkor". Det demokratiska elementet ansågs således kräva ett aktivt deltagande, och i termer av industriell demokrati rörde det arbetarnas inflytande.

Olika former av industriell demokrati hade tidigare genomförts i bland annat Norge och England, därtill hade ett antal försök med driftsråd i privatägda företag gjorts i USA. I Tyskland och Österrike hade bland andra Karl Kautsky och Otto Bauer dragit upp riktlinjer för industriella rådssystem. Visionen kring dessa råd rörde inte endast ett arbetarinflytande för industrin, utan i förlängningen också för hela samhällsekonomin. Emellertid kom den svenska socialdemokratin i huvudsak att intressera sig för den gillesocialism som utvecklats i England under inflytande av den fabianska rörelsen (Lundh 1989: 226-254). Svenska socialdemokrater, däribland Ernst Wigforss och Nils Karleby, genomförde ett antal resor till England för att studera gillenas uppbyggnad och utformning, och för att sedan rapportera hem (se t.ex. Wigforss 1922b). Dessa utländska försök kom dock inte att lämna något större avtryck i det betänkande som den svenska kommittén för industriell demokrati 
presenterade. Enligt ekonomhistorikern Christer Lundh (1987: 282, 493) fanns det inom kommittén en allmän uppfattning om att förhållandena i Sverige skilde sig markant från de nationer som hade deltagit i världskriget. Under hösten 1923 avlämnade kommittén sin slutrapport (Kommittén för industriell demokrati 1923) vilket ledde till debatter i riksdagen det efterföljande året då SAP, inspirerade av kommitténs resultat, lade fram en motion som syftade till att införa industriell demokrati. Det bakomliggande motivet till motionen sades vara att det industriella livet borde följa en utveckling som liknade det politiska.

Den tankegång, som ligger bakom dessa förslag om införandet av s. k. industriell demokrati, plägar ofta uttryckas med den jämförelsen, att det inom det nutida ekonomiska livet måste försiggå en utveckling parallellt med den, som redan ägt rum inom det politiska området, nämligen från envälde till demokratiskt styrelsesätt (Motion nr. 106 i FK 1924: 3).

Det fanns således, enligt SAP, ett tydligt samband mellan industriell demokrati och politisk demokrati. Enligt Wigforss (FK 1924, nr. 45: 75) innebar den politiska jämställdheten, som arbetarna fått i och med rösträttsreformen, att det var "orimligt att tänka sig, att de $[\ldots]$ inte själva verkligen kunna utöva något avgörande inflytande på de företag, av vilkas bestånd de i sista hand äro beroende". Liknande uttalanden gjordes också av andra socialdemokrater, till exempel hävdade Oskar Hagman (1920) att "begreppet industriell demokrati [innebär] en verklig maktförskjutning i de industriella företagen”. I Tiden skrev signaturen Karl Hedmanson ${ }^{1}$ (1921: 113) att idén med industriella råd, som genomförts i England, inte var att betrakta som något annat än ett "undanskjutande av klasskampen". För SAP innebar industriell demokrati en form av exklusiv arbetarmakt. Det deltagande elementet betonades starkt, och det bör betraktas som en central del av svensk socialdemokratis tal om industriell demokrati under det tidiga 1920-talet. Enligt SAP innebar deltagandet i den politiska demokratin att arbetarna också hade en demokratisk rättighet att kontrollera den industriella driften.

Under 1920-talets inledande år argumenterade socialdemokratiska företrädare också för en socialisering, vilket förstods som ett statligt övertagande av produktionsmedlen, för att nå det samhälle 
som kallades ekonomisk demokrati. Förutom Kommittén för industriell demokrati tillsatte den socialdemokratiska regeringen också en kommitté som skulle utreda den så kallade Socialiseringsfrågan (Socialiseringsnämndens handlingar 1920, vol. 3). Socialisering användes ofta synonymt med ekonomisk demokrati, ett begrepp som partiets företrädare på olika vis sammankopplade med politisk demokrati. Till exempel hävdade partiledaren Per Albin Hansson (1920) att: "Ekonomiskt fåvälde och politisk demokrati kunna icke förenas". Genom införandet av distinktionen mellan demokrati och fåvälde tycks det som om ekonomisk demokrati förstods i termer av en jämlik fördelning av den ekonomiska makten. Ett än mer radikalt krav kom från Gustav Möller (1920: 94), tongivande ledamot av partistyrelsen, som hävdade att socialisering innebar att arbetarklassen skulle överta samhällets ekonomiska maktpositioner. Deltagande utgjorde därmed en viktig del i begreppen ekonomisk demokrati och socialisering.

Socialiseringsnämndens arbete kom att bli en lång och utdragen affär där högern och de liberala kom med ständiga krav på dess avsättning. Något lagförslag lyckades nämnden inte presentera, men från socialdemokratiskt håll hördes likväl röster som talade sig varma för ekonomisk demokrati (Olsson \& Ekdahl 2002: 56f). Ekonomisk demokrati var i hög grad det begrepp som föredrogs av Socialdemokraterna när de talade om hur det ekonomiska livet borde följa de regler som upprättats i det politiska (se t.ex. Oljelund 1920; Karleby 1922). Till skillnad från industriell demokrati rörde begreppet ekonomisk demokrati samhället som helhet, och det var således inte avgränsat till någon speciell sfär (Kommittén för industriell demokrati 1923: 18; jfr. Tingsten 1941: 246; Lundh 1987: 26). Därmed förefaller det vara rimligt att betrakta industriell demokrati som en del av begreppet ekonomisk demokrati. Det deltagande elementet betonades tydligt $\mathrm{i}$ användningen av industriell demokrati, vilket också var fallet med ekonomisk demokrati. Vikten av ett medborgerligt deltagande i en ekonomisk demokrati framhölls bland annat av den programkommission som arbetade med att ta fram ett nytt partiprogram inför 1920 års socialdemokratiska partikongress ('P.M. angående ekonomisk demokrati”, Programkommissionen 1920). Det fanns alltså tydliga likheter mellan de sammansatta demokratibegreppen, och i dem alla fanns deltagande med som en central del. 


\section{Det sena 1920-talet: Folkhem, medborgarhem och en demokratisk beskatning}

Under senare hälften av 1920-talet sökte det socialdemokratiska partiet alltmer framstå som ett parti för hela folket snarare än ett arbetarparti. Retoriskt gjordes detta genom att använda begreppen folkhem och medborgarhem som ideologiska verktyg (Björck 2011). Denna förvandling av Europas socialistiska partier hade påbörjats under första världskriget, då socialister tog plats i ett antal regeringar, inte för att genomföra någon socialistisk revolution, utan snarare för att skydda de existerande nationerna. Under världskriget byttes arbetarretoriken gradvis ut mot ett mer nationellt och patriotiskt tilltal. Till exempel använde det tyska Sozialdemokratische Partei Deutchlands tydliga nationalistiska referenser i hopp om att nationalismen skulle fylla luckan mellan arbetarklassen och resten av nationen (Sassoon 2002: 43-47; Berman 2006: 88f). Enligt idéhistorikern Tomas Jonsson (2000: 323-344) löste användningen av begreppet folkhem en intern konflikt för SAP, det vill säga mellan strävan efter röstmaximering i de politiska valen och det ideologiska arvet av att vara ett arbetarklassparti. I folkhemmet upplöstes klasskampen då människorna i första hand var medborgare snarare än arbetar- eller borgarklass. Samtidigt uppfattades det fullständigt demokratiserade samhället allt mer som det ideala samhället då det ansågs kunna lösa de existerande klasskonflikterna. Den nära relationen mellan medborgarhemmet och demokrati påtalades explicit i Per Albin Hanssons (AK 1928, nr. 3: 11f) numer klassiska tal i andra kammarens remissdebatt den 18 januari 1928.

Hemmets grundval är gemensamheten och samkänslan. Det goda hemmet känner icke till några privilegierade eller tillbakasatta, inga kelgrisar och inga styvbarn. [...] I det goda hemmet råder likhet, omtanke, samarbete, hjälpsamhet. Tillämpat på det stora folk- och medborgarhemmet skulle detta betyda nedbrytandet av alla sociala och ekonomiska skrankor, som nu skilja medborgarna i privilegierade och tillbakasatta, i härskande och beroende, i rika och fattiga, besuttna och utarmade, plundrare och utplundrade. Det svenska samhället är ännu icke det goda medborgarhemmet. Här råder visserligen en formell likhet, likheten i politiska rättigheter, men socialt sett består ännu klassamhället och ekonomiskt råder fåtalets diktatur. [...] Skall 
det svenska samhället bli det goda medborgarhemmet måste klasskillnaden avlägsnas, den sociala omsorgen utvecklas, en ekonomisk utjämning ske, de arbetande beredas andel även i det ekonomiska förvaltandet, demokratin genomföras och tillämpas även socialt och ekonomiskt. [...] Det är den stora uppgiften för en ärlig demokratisk politik att göra samhället till det goda medborgarhemmet. [...] Det måste en gång bli så, att klassamhället Sverige avlöses av folkhemmet Sverige.

Det fanns alltså ett nära samband mellan demokrati och ekonomiska frågor, och det var tydligt att rösträttsreformen inte ansågs tillräcklig för att det svenska samhället skulle kunna betraktas som en fullständig demokrati. För att nå denna fullständiga demokrati behövde demokratin, enligt Hansson, tillämpas även socialt och ekonomiskt; med andra ord behövde den politiska demokratin kompletteras med andra former av demokrati. Hansson (1927) argumenterade också - i den socialdemokratiska dagstidningen $N y$ Tid - för att: "Den allmänna rösträttens största värde ligger för oss däri, att den är ett medel i folkets hand att på fredlig väg genomföra de sociala och ekonomiska omdaningar, som äro nödvändiga om klassamhället en gång skall bli det goda folkhemmet". I hög grad kan medborgarhemmet/folkhemmet betraktas som metaforer, eller synonymer, för det fullständigt demokratiserade samhället, då de egenskaper som medborgarhemmet sades ha i hög grad var desamma som partiet hävdade var demokratiska egenskaper.

Sambandet mellan demokrati och folkhem kom att få praktisk tillämpning i den riksdagsmotion som det socialdemokratiska partiet lade fram 1928 i syfte att åstadkomma en ny arvskattelagstiftning. En högre skatt betraktades som ett steg på vägen mot en ekonomisk utjämning av klasserna, som nämnts i Hanssons folkhemstal, och därmed sågs den också som ett steg närmare en ekonomisk demokrati. I motionen (nr. 157 i FK 1928: 12) stod att läsa att den dåvarande egendomsfördelningen var omöjlig att försvara eftersom den stod i direkt strid med "de mest elementära begrepp om demokrati och social rättvisa". Demokrati krävde, enligt SAP, en rättvis distribution av privat egendom, och denna rättvisa uppfattades av partiet som en total utjämning. I Hanssons medborgarhem/folkhem fanns inget utrymme för "några privilegierade eller tillbakasatta, inga kelgrisar och inga styvbarn" då alla människor betraktades som lika ur alla synpunkter. För att bygga medborgar- 
hemmet hade Hansson argumenterat för en ekonomisk utjämning. En ny arvsskatt sågs alltså som ett steg på vägen mot denna och en ekonomisk demokrati, och i förlängningen också mot byggandet av folkhemmet. Här bör emellertid framhållas att till skillnad från tidigare socialdemokratiska uttalanden om demokrati betraktades folkhemmet som något som skapades av staten för medborgarna, vilket betyder att begreppet inte förefaller ha innehållit något deltagande element.

I riksdagen debatterades arvsskattemotionen, och den socialdemokratiske ledamoten Anton Björklund (AK 1928, nr. 25: 24) påtalade att: "Man måste öppna blicken för, att om folket ha fått en politisk demokrati, som man i fortsättningen vill behålla, låter sig därmed i längden mycket dåligt förena en ekonomisk diktatur. Ty det är ingenting annat vi leva under för närvarande än en ekonomisk diktatur”. Från socialdemokratiskt håll ansågs det alltså vara en anomali att ha demokrati i en samhällssfär, den politiska, men samtidigt acceptera att de demokratiska principerna inte gavs någon spridning till andra delar av samhället (se t.ex. FK 1928, nr, 24: 13; AK 1928, nr. 25: 48). I sin bok Fattiga och rika skrev Ernst Wigforss (1928: 4) att en jämlik fördelning av privat egendom inte endast var den mest demokratiska fördelningen, utan även den mest rationella, vilket ledde honom till slutsatsen att denna också var den bästa formen av fördelning. Emellertid innebar detta att det deltagande elementet, som tidigare varit av central betydelse för demokrati, förflyttades till periferin, då fördelning av egendom var något som staten kontrollerade. Arvsskattemotionen kom dock att röstas ned i riksdagen, och den skulle senare leda till att det socialdemokratiska partiet anklagades för kommunism av de borgerliga partierna inför riksdagsvalet på hösten 1928 där SAP förlorade ett flertal mandat (Möller 2004: 105-111; Hadenius 2008: 50ff).

Under intryck av valförlusten 1928, och den massiva kritik som partiet fick under valrörelsen, kom SAP att använda begreppet ekonomisk demokrati i allt mindre utsträckning (Friberg 2013: 186f). Istället fortsatte partiet att manifestera sig som ett parti för hela folket, och folkhemmet gavs allt mer statusen som SAP:s övergripande mål. Partiet fortsatte emellertid att argumentera för en reform av det ekonomiska livet, men detta gjordes med hjälp av andra begrepp än ekonomisk demokrati eller industriell demokrati. Under 
intryck av ett allt oroligare läge i Europa, och en växande aversion mot Sovjetunionen, sökte SAP undvika begrepp som kunde sammankopplas med den radikala socialism som lett till revolutioner och samhällsomstörtningar i Europa (Jonsson 2000: 283-366; Friberg 2013: 190f, 224-229). I hög grad kan det socialdemokratiska partiet sägas ha integrerat sitt breda demokratibegrepp under folkhemsbegreppet. Processen innebar dock att demokratibegreppet förlorade det deltagande elementet som tidigare utgjort en av dess mer centrala komponenter. Demokrati uppfattades $i$ allt högre grad som något som gavs från staten till medborgarna snarare än något som krävde ett aktivt medborgerligt deltagande.

\section{Sammanfattende kommentarer: Demokrati utan deltagande?}

Undersökningen har visat hur de svenska Socialdemokraterna nyttjade demokratibegreppet efter rösträttsreformen 1919/1921. Tydligt är att demokrati, för SAP, representerade något mer än en beslutsordning - det var ett begrepp som gavs relevans genom hela samhället. Emellertid förefaller en motsättning ha uppstått mellan partiets ideologiska socialism och demokratin som en huvudprincip. Då SAP tolkade den socialistiska principen om solidaritet som en jämlikhetsprincip - vilket bland annat synliggjordes i 1928 års arvsskattemotion - innebar det att det alltid varit möjligt att ställa ökade krav på ett så kallat demokratiskt samhälle, eftersom det alltid går att utkräva större samhällelig jämlikhet. Detta innebär att demokratiseringen av samhället, för Socialdemokraterna, alltid blir ett pågående och därmed också odefinierbart projekt.

De sammansatta demokratibegrepp som de svenska Socialdemokraterna använde sig av efter rösträttsreformen kunde alla sammankopplas med den politiska demokratisering som ägt rum, där ett medborgerligt deltagande varit av största vikt. Industriell demokrati användes för att argumentera för att arbetarna skulle styra industrin, medan ekonomisk demokrati sammankopplades med en strävan efter en mer jämlik fördelning av ekonomisk makt. I dessa demokratibegrepp utgjorde deltagande således en viktig del. I talet om en ny arvsskattelagstiftning kom dock begreppet ekonomisk demokrati att förändras då det deltagande elementet gavs 
en mer perifer status. Än tydligare blev det genom användningen av folkhemmet/medborgarhemmet då demokrati allt mer förstods som något som gavs från staten till medborgarna snarare än något som de själva skapade. Demokrati tycks alltså inte längre ha innehållit något deltagande element.

Om demokrati kan förstås som folkstyre, vilken typ av demokrati talade SAP då om när de integrerade begreppet under sitt folkhemsbegrepp? Det förefaller som om en diskrepans uppstod - mellan demokrati, förstått i termer av folkstyre, och det statliga byggandet av folkhemmet. Denna kan dock förklaras genom en analys av det deltagande elementet under det tidiga 1920-talet. Industriell demokrati var något som, enligt SAP, skulle skapas på arbetsplatserna av de arbetande själva, och begreppet innehöll därmed ett tydligt deltagande element. Emellertid var ekonomisk demokrati, förstått som deltagande i den ekonomiska makten, snarare av typen passivt, eller statsgivet, deltagande. Det var med andra ord någonting som staten möjliggjorde för medborgarna. Det socialdemokratiska partiet förefaller inte ha upplevt något motsatsförhållande mellan skapandet av demokrati och ett ovanifrånperspektiv. Demokrati var något som kunde skapas från flera samhälleliga nivåer: både av medborgarna själva och av statens hand. Begreppet inkluderade alltid ett deltagande element, men precis som i fallet med demokratin fanns det demokratiska deltagandet $\mathrm{i}$ två former; det kunde vara både aktivt och passivt.

\section{Noter}

1 Karl Hedmanson var en pseudonym för författaren Gösta Pauve.

\section{Litteratur}

Alexius, Katarina (1997): Politisk yttrandefribet: En studie i lagstiftning och praxis under demokeratins genombrottstid, Uppsala: Institutet för rättshistorisk forskning, Uppsala universitet.

Arbetarrörelsens arkiv och bibliotek, Sveriges socialdemokratiska arbetareparti, Handlingar rörande programrevision 1920, vol. 1889, F09:01.

Berman, Sheri (2006): The Primacy of Politics: Social Democracy and the Making of Europe's Twentieth Century, Cambridge: Cambridge University Press. 
Björck, Henrik (2011): 'Det politiska folkhemsbegreppet: Tillkomstens kontexter" i Andrén, Mats, Björck, Henrik, Kärnfelt, Johan \& Rosengren, Cecilia (red.), Språket $i$ historien, historien $i$ språket: En vänbok till Bo Lindberg, Göteborg: Institutionen för litteratur, idéhistoria och religion, Göteborgs universitet, s. 377-393.

Bonn, Moritz J. (1925): Die Krisis der europäischen Demokratie, München: Meyer $\&$ Jessen.

Bryce, James (1929): Modern Democracies, London: Macmillan.

Dahl, Robert (2000): On Democracy, New Haven: Yale University Press.

Eley, Geoff (2002): Forging Democracy: The History of the Left in Europe, 18502000, Oxford: Oxford University Press.

Freeden, Michael (2008): Ideologies and Political Theory: A Conceptual Approach, Oxford: Oxford University Press.

Friberg, Anna (2013): Demokrati bortom politiken: En begreppshistorisk analys av demokratibegreppet inom Sveriges socialdemokratiska arbetareparti 1919-1939, Stockholm: Bokförlaget Atlas.

Hadenius, Stig (2008): Sveriges politiska historia frän 1865 till våra dagar: Konflikt och samförstån, Stockholm: Hjalmarson \& Högberg.

Hagman, Oskar (1920): "Klargörande debatter på Köpenhamnskongressen", Social-Demokraten 23/1.

Hallin, Erik (1919): "Arbetsintensitetens problem och den ekonomiska demokratin", Tiden, nr. 3, s. 97-110.

Hansson, Per Albin (1920): "Ekonomiskt fåvälde och politisk demokrati kunna icke förenas", Social-Demokraten 25/6.

Hansson, Per Albin (1927): "Det sociala missnöjet", Ny Tid 8/9.

Hedmanson, Karl (1921): "Produktionens utvecklingslinje: Ytterligare socialistisk självprövning", Tiden, nr. 3, s. 112-116.

Isaksson, Anders (1990): Per Albin: 2. Revolutionären, Stockholm: Wahlström \& Widstrand.

Isaksson, Anders (1996): Per Albin: 3. Partiledaren, Stockholm: Wahlström \& Widstrand.

Jonsson, Tomas (2000): "Att anpassa sig efter det möjliga": Utsugningsbegreppet och SAP:s ideologiska förändringar 1911-1944, Göteborg: Institutionen för idéoch lärdomshistoria, Göteborgs universitet.

Karleby, Nils (1922): "Arbetslöshetsproblemets kärnpunkter", Tiden, nr. 4, s. 193-210.

Karleby, Nils (1924): 'Samhället", Tiden, nr. 4, s. 234-243.

Kommittén för industriell demokrati (1923): Den industriella demokratiens problem: 1. Betänkande jämte förslag till lag om driftsnämnder, SOU 1923:29.

Koselleck, Reinhart (2004): Futures Past: On the Semantics of Historical Times, New York: Columbia University Press. 
Kurki, Milija (2010): 'Democracy and Conceptual Contestability: Reconsidering Conceptions of Democracy in Democracy Promotion", International Studies Review, vol. 12, nr. 3, s. 362-386.

Kurunmäki, Jussi (2012): "The Lost Language of Democracy: Anti-rhetorical Traits in Research on Democratisation and the Interwar Crisis of Democracy", Res Publica: Revista de Filosofía Politica, vol. 15, nr. 27, s. 121-130.

Lakoff, Sanford (1996): Democracy: History, Theory, Practice, Boulder, Colorado: Westview Press.

Loewenstein, Karl (1938): "Legislative Control of Political Extremism in European Democracies I", Columbia Law Review, vol. 38, nr. 4, s. 591-622.

Lundh, Christer (1987): Den svenska debatten om industriell demokrati 1919-1924: I. Debatten i Sverige, Lund: Studentlitteratur.

Lundh, Christer (1989): Den svenska debatten om industriell demokrati 1919-1924: II. Utländska inspirationskällor, Lund: Studentlitteratur.

Magnusson, Lars (2000): "Den svenska arbetslösheten i ett längre perspektiv", Ekonomisk debatt, vol. 28, nr. 1, s. 33-42.

Mannheim, Karl (1936): Ideology and Utopia: An Introduction to the Sociology of Knowledge, London: Routledge and Kegan Paul.

Möller, Gustav (1920): 'Socialiseringsproblemen", Tiden, nr. 3, s. 97-105.

Möller, Tommy (2004): Svensk politisk historia 1809-1975, Lund: Studentlitteratur.

Nevers, Jeppe (2011): Fra skaldsord til slagord: Demokratibegrebet i dansk politisk historie, Odense: Syddansk Universitetsforlag.

Oljelund, Ivan (1920): "Om demokratin", Social-Demokraten 17/3.

Olsson, Lars \& Ekdahl, Lars (2002): Klass i rörelse: Arbetarrörelsen i svensk sambällsomvandling, Stockholm: Arbetarrörelsens arkiv och bibliotek.

Olsson, Oscar (1920): "Socialismens kultursamhälle", Tiden, nr. 5-6, s. 238-246.

Olsson, Stefan (2000): Den svenska bögerns anpassning till demokratin, Uppsala: Acta Universitatis Upsaliensis.

Palmstierna, Erik (1919): 'Ekonomisk demokrati”, Tiden, nr. 2, s. 49-53.

Premfors, Rune (2003): Democratization in Scandinavia: The Case of Sweden, Stockholm: Stockholms centrum för forskning om offentlig sektor, SCORE.

Riksarkivet, Socialiseringsnämndens handlingar 1920, vol. 3.

Riksdagens protokoll med bihang $(1924,1928)$.

Sassoon, Donald (2002): Hundra år av socialism: Vänstern i Europa under 1900-talet, Stockholm: Atlas.

Schiller, Bernt (1988): Samarbete eller konflikt, Stockholm: Arbetsmiljöfonden.

Segerstedt, Torgny (1933): Demokrati och diktatur, Stockholm: Bonnier.

Stråth, Bo (1996): The Organisation of Labour Markets: Modernity, Culture and Governance in Germany, Sweden, Britain and Japan, London: Routledge.

Sydow, Björn von (1997): Parlamentarismen i Sverige: Utveckling och utformning till 1945, Stockholm: Gidlunds förlag i sammanbete med Riksbankens jubileumsfond. 
Thorsson, Fredrik (1920): 'Inför en ny epok i arbetarklassens historia", SocialDemokraten 30/7.

Tilly, Charles (2007): Democracy, Cambridge: Cambridge University Press.

Tingsten, Herbert (1933): Demokratiens seger och keris: Den författningspolitiska utvecklingen 1880-1930, Stockholm: Bonnier.

Tingsten, Herbert (1941): Den svenska socialdemokratiens idéutveckling I, Stockholm: Tidens förlag.

Wigforss, Ernst (1920): "Demokratiska problem", Tiden, nr. 5-6, s. 279-293.

Wigforss, Ernst (1922a): Industrins demokratisering, Stockholm: Bokförlaget AB Tidens tryckeri.

Wigforss, Ernst (1922b): "Ett besök hos engelska byggnadsgillen", Tiden, nr. 2, s. 65-91.

Wigforss, Ernst (1928): Fattiga och rika, Stockholm: Tiden. 
